\title{
Localization sites of nuclear envelope SUN2-like proteins in root meristem cells of Allium cepa under hydroxyurea-induced DNA replication stress
}

\author{
Aneta Żabka ${ }^{1} \cdot K_{\text {Konrad Winnicki }}{ }^{1} \cdot$ Justyna Teresa Polit $^{1}$. \\ Joanna Bernasińska ${ }^{2} \cdot$ Janusz Maszewski $^{1}$
}

Received: 8 April 2015/Revised: 9 July 2015/Accepted: 21 July 2015/Published online: 4 August 2015

(C) The Author(s) 2015. This article is published with open access at Springerlink.com

\begin{abstract}
Regardless of the DNA replication stress induced by low concentration of hydroxyurea (HU), root apical meristem cells of Allium cepa keep growing, and some of them override the DNA damage checkpoint mechanisms initiating either premature or an abnormal mitotic chromosome condensation. Prolonged incubation of onion seedlings with HU results in an increased level of immunodetectable proteins sharing epitopes with SUN2, one of the highly conserved elements linking nuclear envelope (NE) to the cytoand nucleoskeletal structures. In addition to NE, phragmoplast and cell plate, our observations extend an array of subcellular compartments at which SUN2-like proteins (SUN2-LPs) are localized. These include cortical preprophase band of microtubules, centromeric regions of ana- and telophase chromosomes, and nuclear bodies (SUN2-NBs) polarly localized in interphase nuclei according to Rabl's configuration. SUN2-
\end{abstract}

Communicated by E. Schleiff.

Janusz Maszewski

jamasz@biol.uni.lodz.pl

Aneta Żabka

zabkka@poczta.onet.pl

Konrad Winnicki

winnicki@biol.uni.lodz.pl

Justyna Teresa Polit

justpoli@biol.uni.lodz.pl

Joanna Bernasińska

joannab@biol.uni.lodz.pl

1 Department of Cytophysiology, Faculty of Biology and Environmental Protection, University of Łódź, Pomorska 141/143, 90-236 Łódź, Poland

2 Department of Thermobiology, Institute of Biophysics, Faculty of Biology and Environmental Protection, University of Łódź, Pomorska 141/143, 90-236 Łódź, Poland
NBs (distinct from fibrillarin-rich Cajal bodies) colocalize with late-replicating areas of heterochromatin and are thought to represent clustered centromeres. Three-dimensional spatial analysis of SUN2-NBs suggests their connections with NE. An enhanced expression and additional localization sites of SUN2-LPs may be correlated with a considerable reprogramming of cellular functions triggered in response to prolonged HU treatment.

Keywords Allium cepa $\cdot$ Hydroxyurea $\cdot$ Nuclear envelope - Preprophase band DNA replication stress . SUN2-like proteins

$\begin{array}{ll}\text { Abbreviations } \\ \text { ATM } & \text { Ataxia-telangiectasia mutated } \\ \text { ATR } & \text { ATM-Rad3-related } \\ \text { BSA } & \text { Bovine serum albumin } \\ \text { EdU } & \text { 5-Ethynyl-2'-deoxyuridine } \\ \text { IM } & \text { Interphase/mitotic (cells or chromosomes) } \\ \text { NB } & \text { Nuclear body } \\ \text { NE } & \text { Nuclear envelope } \\ \text { PCC } & \text { Premature chromosome condensation } \\ \text { PPB } & \text { Preprophase band } \\ \text { RAM } & \text { Root apical meristem } \\ \text { SUN2-LP } & \text { SUN2-like protein } \\ \text { SUN2-NB } & \text { SUN2-LP-containing nuclear body }\end{array}$

\section{Introduction}

Recent experiments using long-term treatment of onion (Allium cepa) seedlings with low concentrations of $\mathrm{HU}$ have shown that despite persistent replication stress, a 
considerable number of root apical meristem (RAM) cells override the S-M checkpoint and initiate either premature chromosome condensation (PCC) or an unusual nuclear division forming half interphase/half mitotic chromosomes (IM cells; Żabka et al. 2010). Both abnormal types of M-phase cells have been considered as the final outcome of three successive phases including: (1) an inhibitory stage directly caused by the impaired DNA synthesis, (2) an adaptation to the DNA replication stress, and (3) a recovery stage, during which some cells restore their lost functions despite the continued presence of the drug (Żabka et al. 2012). Consequently, the early observed effects of HU consist in a decreased frequency of mitotic divisions, which is succeeded by a period of constant cell enlargement. This in turn is followed by a renewed rise in mitotic activity, resulting in a high degree of diversity among root meristem cells, with the dominant population of S/G2 phase cells and a minor fraction of M-phase cells with both normal and abnormal morphology of their chromosomes. The appearance of aberrant mitotic structures has been interpreted as a consequence of adaptation processes which abrogate the DNA stress response pathway and allow cell cycle progression regardless of the incomplete DNA replication (Żabka et al. 2012, 2013).

Continuous treatment of primary roots with low doses of HU results in $\gamma$-phosphorylation of H2AX histones (Rybaczek and Maszewski 2007; Żabka et al. 2012), which is regarded as one of the earliest events critical for recognition and repair of DNA damage in eukaryotes (Paull et al. 2000; Stiff et al. 2004). The key role in these processes is played by three sensor kinases related to phosphoinositide 3-kinase (PI3K): ataxia-telangiectasia mutated (ATM), ATM-Rad3-related (ATR), and DNA-dependent protein kinase (DNA-PK), which is essential for the repair of DNA double-strand breaks (Bensimon et al. 2011; Liu et al. 2012). Recent screening studies in mammalian cell systems have demonstrated interactions between SUN-domain proteins and a conserved ATM-, ATR-, and DNA-PKmediated mechanism that function in cell cycle checkpoints to ensure genome integrity (Lei et al. 2012). Considering these data, our current studies were designed to evaluate the effect of long-term HU treatment (conducted during 3 consecutive 24-h periods) on the immunolocalization of SUN2 proteins (termed here as SUN2-like proteins), which connect functionally nuclear envelope (NE) to the cyto- and nucleoskeletal structures (Evans et al. 2011).

Over the past few years, SUN-domain proteins have been characterized in several plant species, including Oryza sativa (Moriguchi et al. 2005), Physcomitrella patens, Arabidopsis thaliana (AtSUN1 and AtSUN2), and Vitus vinifera (Graumann et al. 2010; Graumann and Evans
2010, 2011). In Zea mays, a family of five $S U N$ genes was divided into 2 classes: ZmSUN1/2 comprising structural homologs of the animal and fungal genes, and ZmSUN3-5 representing specific variant genes for SUN-domain proteins expressed at relatively low levels in different tissues of maize (Murphy et al. 2010; Murphy and Bass 2012). Bioinformatic analyses indicate that AtSUN1 and AtSUN2 belong to the canonical C-terminal SUN-domain proteins sharing similar structural features with SUN-domain proteins in humans, animals (Caenorhabditis elegans and Mus musculus) and fungi. Their conserved sequences include a nuclear localization signal and coiled-coil motif that facilitates formation of homomers and heteromers, thus increasing the number and diversity of other SUN-binding partners (Wang et al. 2006; Graumann et al. 2010; Tatout et al. 2014). While the essential roles of SUN1/2 proteins seem to be preserved in evolution, it is still the very beginning of the search for their plant-specific functions determining structural relationships between cell nucleus and the cytoplasm and a variety of regulatory processes engaged in the stress response activities and cellular differentiation.

This work presents data indicating that considerable reprogramming of nuclear functions under prolonged DNA replication stress is correlated with the transient enhancement of the expression of SUN2-like proteins localized predominately in nuclear membranes, phragmoplast and cell plate. In addition to the already well-established subcellular sites of SUN2 proteins, epitopes recognized by anti-SUN2 antibodies were also found in the pericentric areas of mitotic chromosomes and in microtubular arrays forming preprophase bands (PPBs). In interphase, antigenic determinants of SUN2 proteins were found concentrated in nuclear bodies (SUN2-NBs), presumably corresponding to late-replicating domains of pericentric heterochromatin. Three-dimensional confocal analysis of HU-treated onion RAM cells suggests possible structural connections between SUN2-NBs and the inner NE membrane.

\section{Materials and methods}

\section{Plant material}

Seeds of Allium cepa L. (from horticulture farm in Lubiczów) were sterilized using sodium hypochlorite $(0.3 \% \mathrm{v} / \mathrm{v})$, sown on moist filter paper and germinated at room temperature. Selected dark-grown seedlings with primary roots reaching $1.5 \pm 0.2 \mathrm{~cm}$ were cultivated at $20{ }^{\circ} \mathrm{C}$ in Petri dishes $(\varnothing 6 \mathrm{~cm})$ filled with $10 \mathrm{~mL}$ of either distilled water (control samples) or $0.75 \mathrm{mM}$ HU solution (for 24,48 and $72 \mathrm{~h}$, without renewal of the medium, as 
described by Żabka et al. (2012). During incubations, roots were permanently aerated by gentle rotation of Petri dishes (20 r.p.m.).

\section{Feulgen staining and differential interference contrast (DIC) microscopy}

Roots were fixed in an ice-cold mixture of absolute ethanol and glacial acetic acid (3:1, v/v) for $1 \mathrm{~h}$, washed several times with ethanol, rehydrated, hydrolyzed in $4 \mathrm{M} \mathrm{HCl}$ $(1 \mathrm{~h})$, and stained with Schiff's reagent (pararosaniline; Sigma) according to the standard methods (Źabka et al. 2010). After washing with $\mathrm{SO}_{2}$ solution (3 times) and distilled water, excised 1.5-mm-long root tips were placed in a drop of $45 \%$ acetic acid and squashed onto microscope slides. Following freezing with dry ice, coverslips were removed, and the dehydrated dry slides were embedded in Canada balsam before examination. For observations using DIC microscopy (Eclipse 90i; Nikon), apical segments of onion roots were hydrolyzed $(4 \mathrm{M} \mathrm{HCl}$, $1 \mathrm{~h}$ ), squashed, and embedded in glycerol-distilled water mixture $(3: 1, \mathrm{v} / \mathrm{v})$.

\section{Western blotting}

Root tip cells from the control and HU-treated seedlings were lysed using a P-PER Plant Protein Extraction Kit (Pierce) supplemented with Protease Inhibitor Cocktail (Sigma-Aldrich) according to supplier's instructions. The samples were cleared by centrifugation, and total protein extracts, fractionated on $4-12 \%$ Bis Tris/2-(4-morpholino)-ethanesulfonic acid SDS-NuPAGE Novex gel (Invitrogen), were blotted onto polyvinylidene fluoride membrane (0.2- $\mu \mathrm{m}$ pore size; Invitrogen). SUN2-LPs were detected with the rabbit polyclonal anti-SUN2 IgG fraction (Sigma) diluted to 1:1000 using the Chromogenic Western Blot Immunodetection Kit (Invitrogen). Band intensities of SUN2-like proteins and Ponceau S solution-stained proteins (loading control) were quantified by densitometry.

\section{Immunocytochemical detection of SUN2-LPs in whole root tip cells and in isolated nuclei}

Onion seedlings were fixed for $30 \mathrm{~min}\left(20^{\circ} \mathrm{C}\right)$ in PBSbuffered $4 \%$ paraformaldehyde supplemented with $100 \mathrm{mM}$ DTT and washed with PBS. Then, excised root tips were either macerated for $45 \mathrm{~min}$ or squeezed in a drop of PBS between two microscope slides to collect nuclear samples (according to Żabka et al. 2013) that were dropped onto Super Frost Plus glass slides (Menzel-Gläser, Germany) and air dried. For maceration, root tips were incubated with the citrate-buffered mixture ( $\mathrm{pH} 5.0 ; 40{ }^{\circ} \mathrm{C}$ ) containing $2.5 \%$ pectinase from Aspergillus niger (Fluka), $2.5 \%$ cellulase Onozuka R-10 from Trichoderma viride (Serva), and $2.5 \%$ pectolyase Y-23 (ICN) and placed directly onto slides. Both types of slides were treated for $1 \mathrm{~h}$ in permeabilization buffer ( $1 \%$ Triton $\mathrm{X}-100,1 \mathrm{mM}$ EDTA-NaOH, and $1 \% \mathrm{BSA}$ in PBS; room temperature) and for $2 \mathrm{~h}\left(30{ }^{\circ} \mathrm{C}\right)$ in the blocking buffer (3\% BSA, $1 \mathrm{mM}$ EDTA-NaOH, $0.1 \%$ Tween-20, $1 \mathrm{mM}$ DTT in PBS), which was followed by an overnight incubation $\left(4{ }^{\circ} \mathrm{C}\right)$ with rabbit polyclonal anti-SUN2 antibodies (Sigma) dissolved in the same buffer (1:100). After four washes with PBS (15 min each), macerated root tip cells were incubated for $1 \mathrm{~h}$ with goat anti-rabbit IgG conjugated to Alexa Fluor ${ }^{\circledR} 488$ (1:1000; Cell Signaling), while isolated nuclei were incubated with anti-rabbit IgG conjugated to Alexa Fluor ${ }^{\circledR} 555$ or with alkaline phosphatase (AP)-conjugated goat anti-rabbit IgG (1:1000; Sigma). All antibodies were dissolved in the blocking buffer. Incubations were done at room temperature and then followed by several washes with PBS. Slides incubated with Alexa Fluor $^{\circledR}$ 488- and Alexa Fluor ${ }^{\circledR}$ 555-conjugated secondary antibodies were counterstained with PI and DAPI, respectively, and embedded in PBS/glycerol mixture (9:1) containing 2.5\% 1,4-diazabicyclo [2.2.2] octane (DABCO). Following AP-staining developed with BCIP/NBT solution, slides were embedded in a glycerol/PBS mixture (3:1, $\mathrm{v} / \mathrm{v})$.

\section{Co-localization of SUN2-LP and fibrillarin}

Immunodetection of SUN2-LPs in isolated RAM cell nuclei obtained from the control and HU-treated onion seedlings was performed as described earlier, using a secondary goat anti-rabbit antibody conjugated to Alexa Fluor ${ }^{\circledR} 555$ (1:1000; Cell Signaling). Microscopic slides were then washed with PBS and preincubated for 50 min with PBS-buffered $8 \%$ BSA (v/w) and $0.1 \%$ Triton X100 (v/v) and, after rinsing in PBS, incubated overnight with mouse anti-fibrillarin antibody (1:500; Thermo Fisher). Following washing with PBS, slides were incubated for $1 \mathrm{~h}$ with goat anti-mouse Alexa Fluor ${ }^{\circledR} 488$ (1:350; Cell Signaling), and mounted in PBS/glycerol/DABCO mixture.

\section{Co-localization of SUN2-LP and EdU-labeled heterochromatin}

Onion seedlings were incubated for $20 \mathrm{~min}$ with $10 \mu \mathrm{m}$ 5-ethynyl-2'-deoxyuridine (EdU) in the dark. Then, excised 1.5-mm-long root tips were fixed in PBS-buffered $4 \%$ paraformaldehyde $\left(4{ }^{\circ} \mathrm{C} ; \mathrm{pH} 7.4\right)$ for $40 \mathrm{~min}$, and cell nuclei were isolated, dropped onto glass slides and air dried. After washing with PBS, nuclear areas containing newly synthesized DNA were visualized using Click-iT ${ }^{\circledR}$ 
DNA Alexa Fluor $^{\circledR} 555$ Imaging Kit (Invitrogen), according to the supplier's instructions. Next, slides were washed 3 times with PBS and pretreated with PBS-buffered $8 \%$ BSA and $0.1 \%$ Triton $\mathrm{X}-100$ for $50 \mathrm{~min}\left(20^{\circ} \mathrm{C}\right)$. Following incubation with rabbit polyclonal anti-SUN2 antibodies (as before), slides were washed with PBS and incubated with Alexa Fluor ${ }^{\circledR} 488$-conjugated goat polyclonal anti-rabbit IgG (1:1000; Cell Signaling), and mounted in PBS/glycerol/DABCO mixture. Computeraided co-localization of SUN2-LP and EdU labeling was made for selected late S-phase cells with polarly separated areas of telomere and centromere domains containing latereplicating heterochromatin.

\section{Immunocytochemical staining of microtubules $(\beta$ - tubulin)}

Microtubular arrays forming preprophase bands were detected using anti-tubulin antibodies according to procedures described earlier (Żabka et al. 2010). In brief, onion seedlings were fixed for $45 \mathrm{~min}\left(20{ }^{\circ} \mathrm{C}\right)$ in PBS-buffered $3.7 \%$ paraformaldehyde solution and then excised root tips were washed with PBS, placed in a pectinase/cellulase/ pectolyase digestion solution and squashed onto slides (as before). Following pretreatment with PBS-buffered $8 \%$ BSA and $0.1 \%$ Triton $\mathrm{X}-100$ for $50 \mathrm{~min}\left(20^{\circ} \mathrm{C}\right)$, slides were incubated with mouse monoclonal anti- $\beta$ tubulin antibodies (Sigma), dissolved in PBS containing $1 \%$ BSA at a dilution of 1:750. After an overnight incubation $\left(4{ }^{\circ} \mathrm{C}\right)$, slides were washed with PBS and incubated for $1.5 \mathrm{~h}$ $\left(18^{\circ} \mathrm{C}\right)$ with secondary goat anti-mouse $\mathrm{IgG}$ conjugated to Alexa Fluor ${ }^{\circledR} 488$ antibody in PBS (1:500; Sigma). Cell nuclei were counterstained with PI and embedded (as before).

\section{Microscopic measurements, observations and analyses}

Observations were made using E-600 epifluorescence microscope (Nikon) equipped with U2 filter (UVB light; $\lambda=340-380 \mathrm{~nm}$ ) for DAPI, B2 filter (blue light; $\lambda=465-496 \mathrm{~nm}$ ) for Alexa Fluor ${ }^{\circledR} 488$, or G2 filter (green light; $\lambda=540 / 25 \mathrm{~nm}$ ) for Alexa Fluor ${ }^{\circledR} 555$ and PI-stained cell nuclei. All images micrographs were recorded at exactly the same time of integration using a DS-Fi1 CCD camera (Nikon). Quantitative analyses and nuclear DNA fluorescence measurements were made after converting color images into greyscale and expressed in arbitrary units as mean pixel value (pv) spanning the range from 0 (dark) to 255 (white) according to described methods (Żabka et al. 2010, 2012). Confocal observations were made with Leica SP8 (Germany) using laser lines $405 \mathrm{~nm} \mathrm{(DAPI)} \mathrm{and}$
553 nm (Alexa Fluor ${ }^{\circledR}$ 555). Images were acquired with HCPL APO x63/1.40 oil. The cell cycle positions (G1, S, and G2 phases) were estimated by microfluorimetric analysis of nuclear DNA content after PI or DAPI staining. In experiments using EdU labeling, late stages of the $\mathrm{S}$ phase were identified according to the EdU incorporation pattern, as described before (Żabka et al. 2012). All immunofluorescence analyses and Western blot assays were repeated at least twice, while other experiments were repeated several times. The total number of analyzed cells for one set of data was always more than 1000 .

\section{Results}

\section{HU-induced DNA replication stress transiently up- regulates expression level of SUN2-like proteins}

As evidenced earlier (Żabka et al. 2010, 2012), prolonged DNA replication stress induced by continuous incubation of onion seedlings with $0.75 \mathrm{mM}$ HU does not affect the rate of root growth. Despite a marked decrease in mitotic activity within the 3-day treatment period, a relatively small amount of cell divisions has been constantly observed, with a significant rise in mitotic index at $72 \mathrm{~h}$ after the start of incubation (Fig. 1a). Throughout that time, some of the RAM cells became considerably elongated, ultimately exceeding the major to minor axis ratios indispensable to commence PCC (Fig. 1b) and to create interphase-mitotic (IM) cell nuclei (Fig. 1c-e). The PCC phenotype, easily recognized by chromosomal breaks (Fig. 1b), is restricted to a group of M-phase cells approaching the maximum length to width ratio less than 2.5, while the emergence of IM morphology (conjoining dispersed and condensed structures of chromatin) can be observed in only a tiny subset of extremely long cells with major to minor axis ratios above a factor of 3.0 (Fig. 1c-e; see also Żabka et al. 2012).

Prior to immunofluorescence investigations on A. серa RAM cells, polyclonal antibody capable of distinguishing human Sad1p/Unc-84 NE protein (bearing a 151 aa. long SUN2-specific sequence localized downstream from the C-terminal SUN domain) was used for Western blotting (WB) tests (Fig. 2a). WB analysis of the total extract from the control onion root tip cells revealed two strong protein bands close to 80 and $90 \mathrm{kDa}$ and a weaker band migrating with the mobility of $44 \mathrm{kDa}$, consistent with the molecular weight predicted for the monomeric form of SUN2 protein in Z. mays (Murphy et al. 2010) and A. thaliana (Graumann et al. 2010). As compared with the control sample, the staining intensity of all three immunoblot bands increased considerably after 24-h incubation with $0.75 \mathrm{mM}$ HU. 

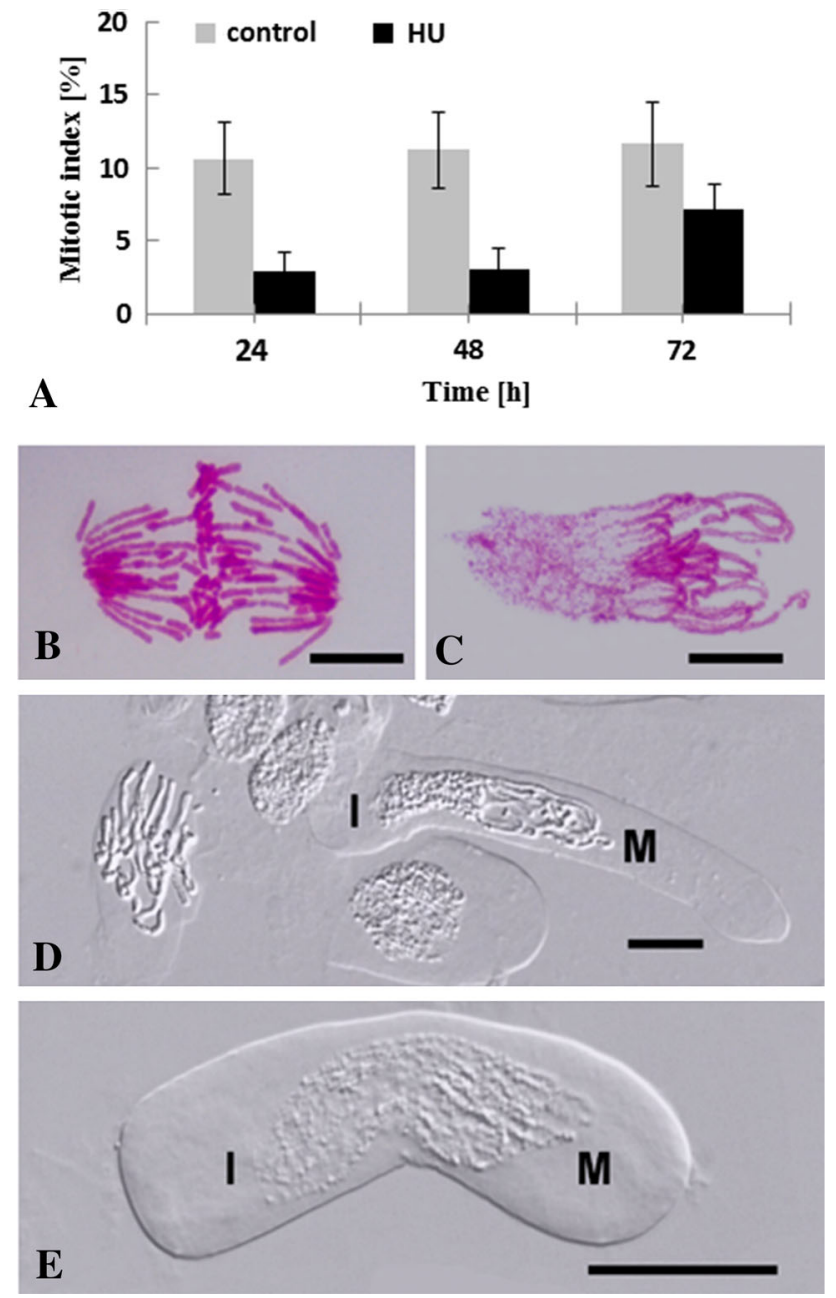

Fig. 1 a Mitotic indices (\%) calculated for A. сера RAM cells after extended time periods in water (control) and in $0.75 \mathrm{mM}$ HU solution (HU). Feulgen-stained chromosomes (b, c) and DIC images (d, e); 72-h HU treatment. b PCC-like aberrations during anaphase. c Gradient of chromatin condensation in a biphasic IM cell. d, e Largely elongated biphasic IM-phase cell with half interphase (I) and half mitotic (M) chromosomes shown using DIC microscopy. Bars $20 \mu \mathrm{m}$

Then, following 48-h treatment, both slower-migrating bands (the $80 \mathrm{kDa}$, and especially the $90 \mathrm{kDa}$ proteins) were still growing, while the $44 \mathrm{kDa}$ band slightly decreased in intensity. After the subsequent treatment with HU (72-h incubation), the $90 \mathrm{kDa}$ band disappeared completely, while the bands located at positions equivalent to molecular weights of 80 and $44 \mathrm{kDa}$ decreased significantly reaching less than half their densities noticed after both shorter incubation periods (Fig. 2a). Even though none of these bands matched WB pattern for SUN1 protein (not shown), we found it more convenient to use the term SUN2-like proteins (SUN2-LPs) because of the unknown structure of SUN-domain proteins in A. cepa and the possible plurality of epitopic binding sites for antibodies used in our studies.

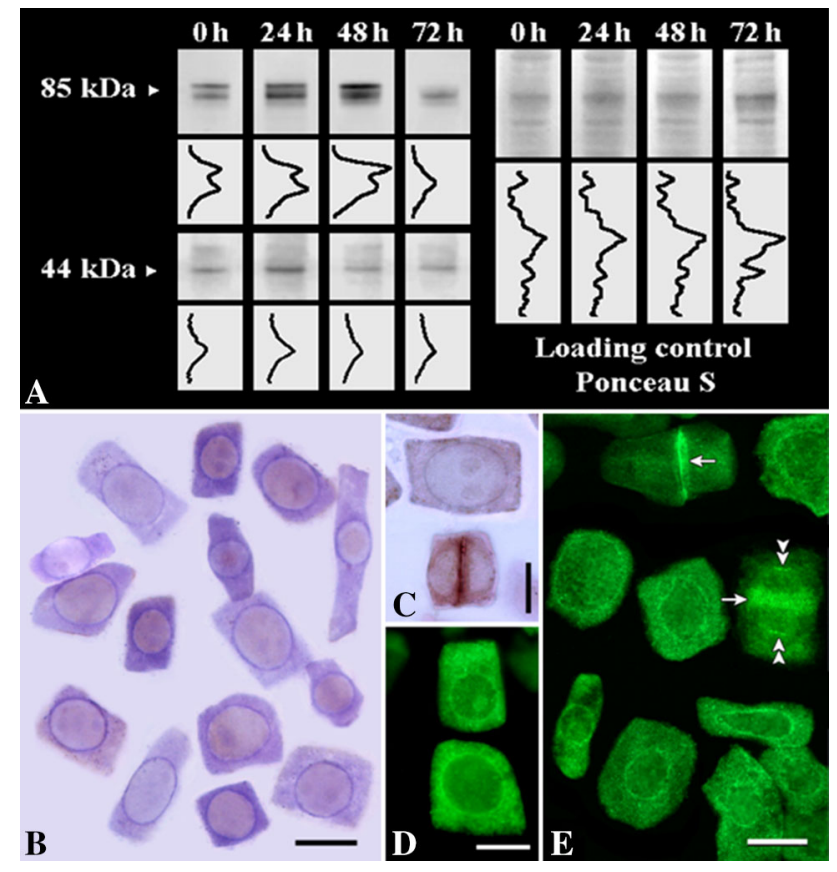

Fig. 2 Immunodetection of SUN2 proteins in A. cepa RAM cells. a Western blots of proteins extracted from the control seedlings $(0 \mathrm{~h})$ and from plants treated for 24,48 , and $72 \mathrm{~h}$ with $0.75 \mathrm{mM} \mathrm{HU}$, and corresponding densitometric scanning of bands located at positions equivalent to molecular weights of about 85 and $44 \mathrm{kDa}$. For loading control, the membrane was stained with Ponceau $\mathrm{S}$ solution. Immunohistochemical staining using anti-SUN2/alkaline phosphatase antibodies (b, c) and immunofluorescence labeling using anti-SUN2/ Alexa Fluor ${ }^{\circledR} 488$ antibodies (green; d, e) of the control (b-d) and HU-treated ( $24 \mathrm{~h}$ incubation) onion RAM cells (e). Note the intense labeling of cell plates (c, e; left turned arrow), phragmoplast (e; right turned arrow) and the centromeric areas of anaphase chromosomes (e; double arrowheads). Bars $10 \mu \mathrm{m}$

\section{Immunolocalization of SUN2-LPs in onion RAM cell nuclei under normal conditions and after prolonged DNA replication stress}

In agreement with previous reports in animal (Hodzic et al. 2004; Schmitt et al. 2007) and plant cells (Graumann et al. 2010), immunoenzymological and immunofluorescence staining of the control onion root meristems revealed a prominent rim-like labeling confined mainly to the $\mathrm{NE}$ (Fig. 2b-d). Specific immunostaining was also observed in the midzone space corresponding to phragmoplast and new cell wall between the two daughter nuclei (Fig. 2c). The analysis of HU-treated RAM cells demonstrated that there is some overlap between quantitative changes in the expression patterns revealed by $\mathrm{WB}$ analysis and the appearance of epitopes recognized by anti-SUN2 antibodies. The increased immunofluorescence observed after the first day of replication stress resulted in an intense staining of the NE and of all other elements specifically labeled in the control cells (i.e. phragmoplasts and cell plates), and 
occasionally, within the centromeric regions of chromosomes during telophase (Fig. 2e).

Immunofluorescence observations of nuclear fractions isolated from both the control and HU-treated onion RAM cells identified new sites of SUN2-LPs, localized within the internal areas of interphase chromatin. Some of them were situated close to the nucleolar region (Fig. 3a-a $\mathrm{a}^{\prime \prime}, \mathrm{b}-\mathrm{b}^{\prime \prime}$ ), but most commonly they were positioned in a polarized manner, reflecting a so-called "Rabl configuration" (Fig. 3a-d). In the untreated samples, mean number of subnuclear regions containing SUN2-LPs (termed as SUN2-nuclear bodies; SUN2-NBs) increased steadily throughout interphase from about 1.4 to less than 4.0 per nucleus (Fig. 3e), with the average diameter up to $1.2 \mu \mathrm{m}$ in G2-phase of the cell cycle (Fig. 3f). The extended duration of HU treatment significantly raised their number (every day by approximately the same percentage relative to the control values estimated for the G2-phase nuclei) and increased their mean size (except day 3, when SUN2-NBs showed no further growth of their diameters).
Consequently, the most prolonged incubation period with $0.75 \mathrm{mM}$ HU brought about an almost threefold increase in the number of SUN2-NBs (Fig. 3e) and an increase in their diameter of nearly 1.5 times (Fig. 3f), when compared to the G2-phase nuclei isolated from the untreated plants.

Supporting evidence for the presence of SUN2-LPs in NE and distinct NBs was provided by confocal microscopy showing specific immunofluorescence confined, respectively, to the nuclear rim and to multiple intranuclear dotlike areas of about $1 \mu \mathrm{m}$ in diameter (Fig. 4a). Three-dimensional spatial analysis of the latter structures suggests that many of them are physically linked to the NE (Fig. 4b-d).

To exclude the possible role of coiled (Cajal) bodies (CBs), which among many NBs seem to be engaged in the recruitment and sequestration of stress-inducible proteins, SUN2-LPs have been colocalized with fibrillarin, an abundant component of several ribonucleoproteins that occur both in the dense fibrillar regions of the nucleoli and in the CBs (Gall 2000; Amin et al. 2007). Although
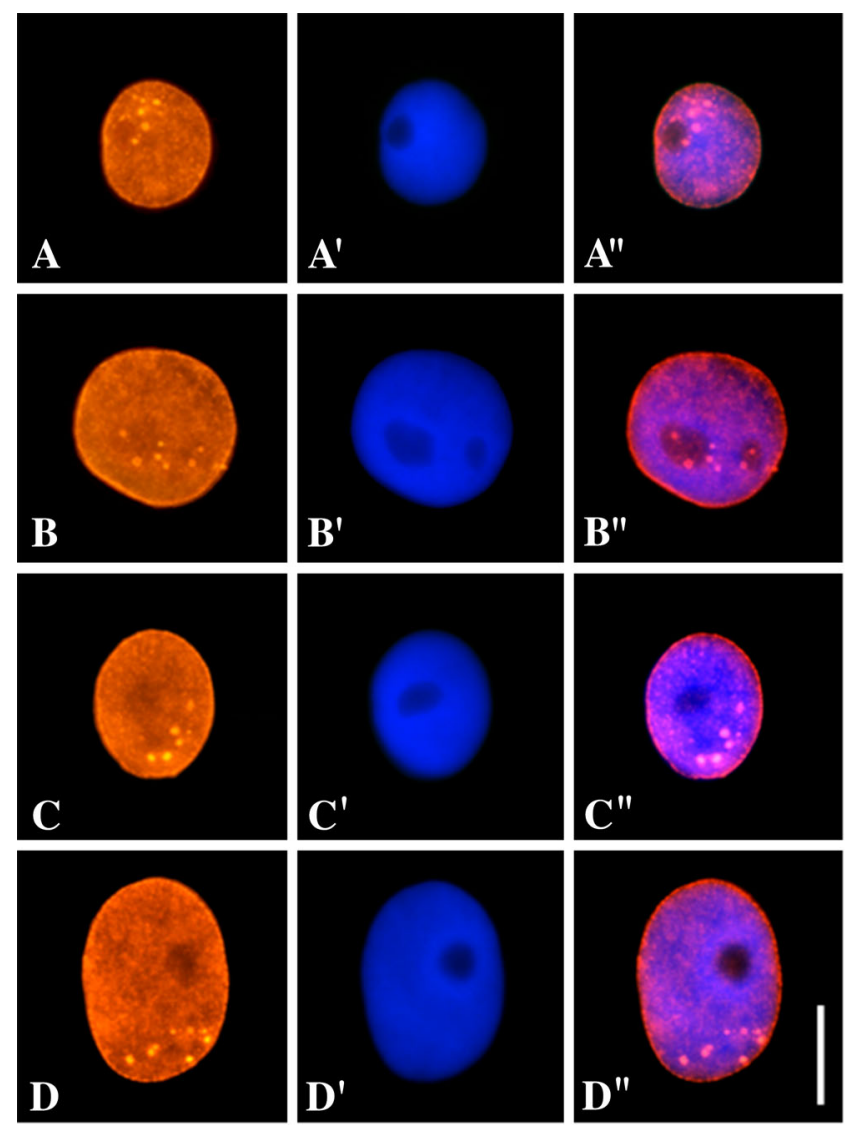
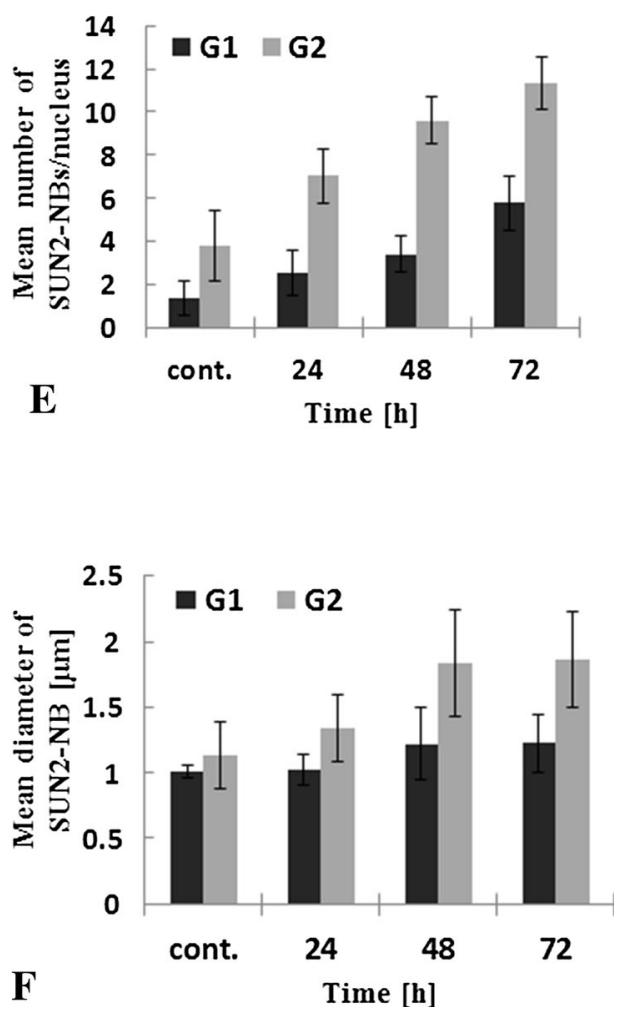

Fig. 3 Immunofluorescence localization of SUN2-LPs (Alexa Fluor ${ }^{\circledR}$ 555 , orange) in nuclear envelopes and nuclear bodies (SUN2-NBs); cell nuclei isolated from the control $(\mathbf{a}, \mathbf{b})$ and HU-treated $(48 \mathrm{~h}$ incubation; c, d) onion RAMs. a, c G1-phase nuclei; b, d G2-phase nuclei. The same nuclei are shown counterstained with DAPI $\left(\mathbf{a}^{\prime}-\mathbf{d}^{\prime}\right.$; blue) and as merged images combining anti-SUN2/DAPI staining $\left(\mathbf{a}^{\prime \prime}-\mathbf{d}^{\prime \prime}\right)$. A close proximity of SUN2-NBs and nucleoli can be seen in the control nuclei $\left(\mathbf{a}^{\prime \prime}-\mathbf{b}^{\prime \prime}\right)$. Bar $10 \mu \mathrm{m}$. Mean number (e) and mean diameters (f) of SUN2-NBs in the G1- and G2-phase root tip cell nuclei isolated from the control seedlings (cont.) and after successive 24,48 , and $72 \mathrm{~h}$ periods of incubation with $0.75 \mathrm{mM} \mathrm{HU}$ 


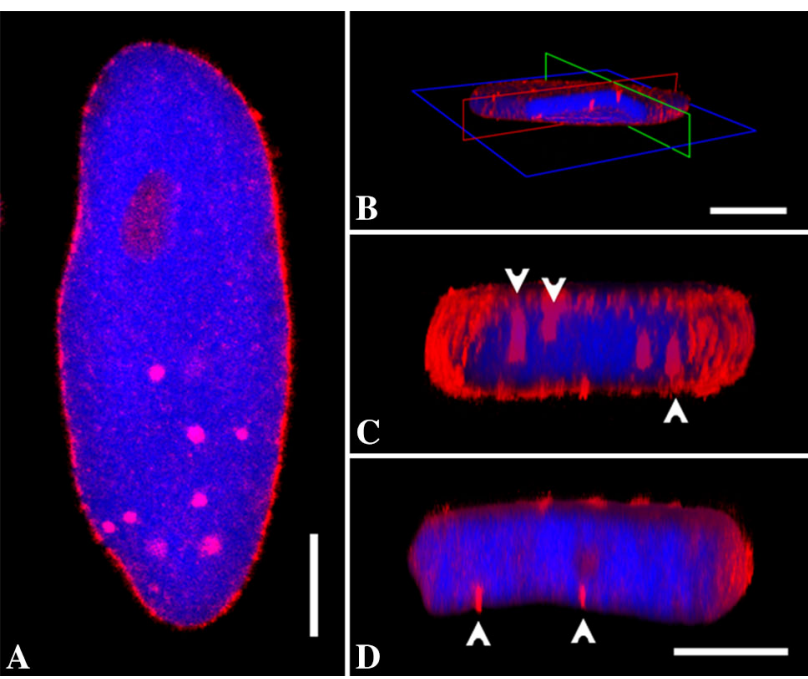

Fig. 4 Confocal immunolocalization of SUN2-LPs (Alexa Fluor ${ }^{\circledR}$ 555, red) in isolated cell nuclei counterstained with DAPI (blue) from HU-treated onion seedling (3-day incubation). G2-phase nucleus with immunolabeled NE and dot-like SUN2-NBs (a). b-d 3-D confocal analysis indicating possible connections between NE and SUN2-NBs (arrowheads in $\mathbf{c}-\mathbf{d}$ ). Bars $10 \mu \mathrm{m}$

microscopic examinations suggest some correlation between the quantities of SUN2-NBs (Fig. 5a-d) and CBs (Fig. $5 \mathrm{a}^{\prime}-\mathrm{d}^{\prime}$; both are more abundant in HU-treated RAM cells and both increase at similar rates in successive stages of interphase), no co-localization of these structures has been found in either the control or the stressed seedlings of A. cepa (Fig. 5a $\mathrm{a}^{\prime \prime}-\mathrm{d}^{\prime \prime}$ ).

Taking into consideration the SUN2-LP-enriched centromeric regions detected in telophase nuclei after 1-day replication stress, our further observations have focused on the fraction of M-phase cells from onion seedlings subjected to more prolonged incubations with $\mathrm{HU}$, resulting in a stronger fluorescence signal. Following 2 days of treatment, most prophase cells revealed distinct rim-like immunolabeling of SUN2 proteins restricted to the NE (Fig. 6a-a $\mathrm{a}^{\prime \prime}$. At metaphase, a significant number of SUN2positive granules were observed in the interchromosomal space surrounding the condensed chromosomes (Fig. 6b$\left.\mathrm{b}^{\prime \prime}\right)$. Subsequently, when sister chromatids were pulled apart toward the opposite ends of the cell in anaphase A, SUN2-LPs were found accumulating in the spindle pole regions (Fig. 6c- $\mathrm{c}^{\prime \prime}$ ). During anaphase B (Fig. 6d- $\mathrm{d}^{\prime \prime}$ ) and telophase (Fig. 6e- $\mathrm{e}^{\prime \prime}$ ), distinct immunolabeling occurred at positions corresponding to the pericentric regions of individual chromosomes. Concurrently, an intense immunofluorescence of SUN2-LP appeared concentrated in the internuclear space occupied by the cytokinetic spindle and in the emerging cell plate.

Our further experiments were designed to verify the presumed link between the SUN2-immunopositive pericentric regions seen at late stages of mitosis and the SUN2-
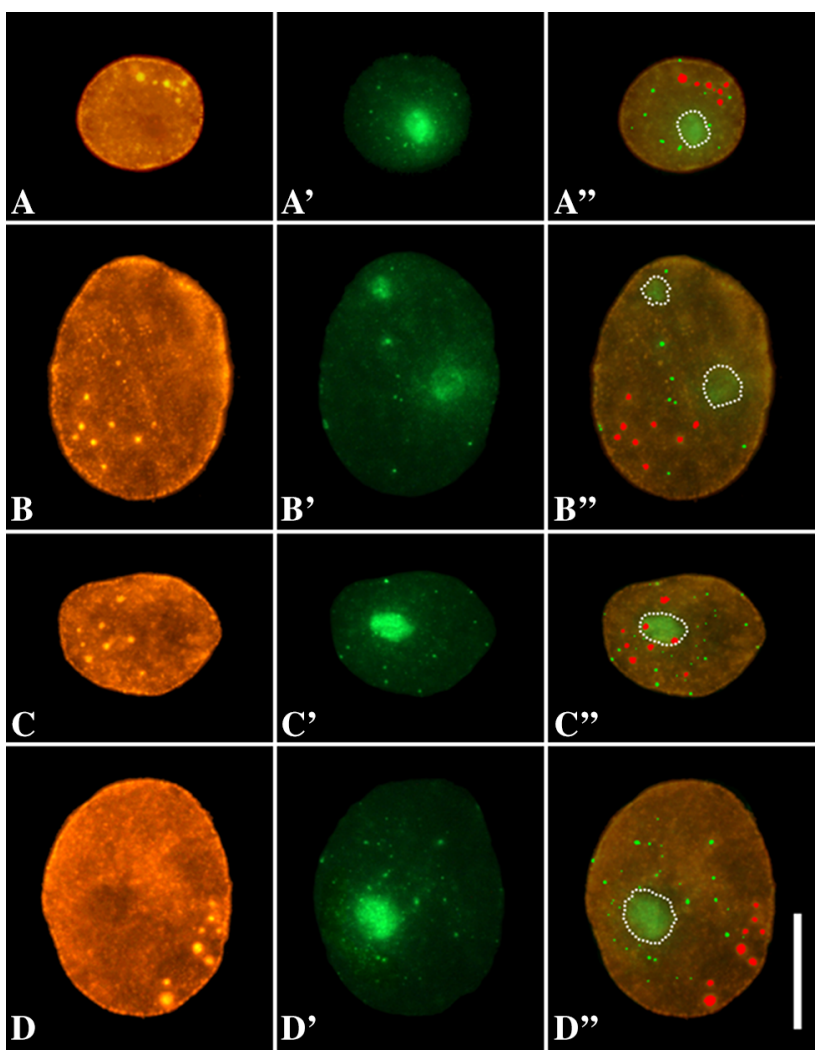

Fig. 5 Double immunofluorescence localization of SUN2 (a-d; Alexa Fluor ${ }^{\circledR} 555$, orange), fibrillarin $\left(\mathbf{a}^{\prime}-\mathbf{d}^{\prime}\right.$; Alexa Fluor ${ }^{\circledR} 488$, green) in cell nuclei isolated from the control $(\mathbf{a}, \mathbf{b})$ and HU-treated (c, $\mathbf{d}$; $48 \mathrm{~h}$ incubation) onion RAMs. The same merged images ( $\mathbf{a}^{\prime \prime}-$ $\mathbf{d}^{\prime \prime}$ ) are shown with red marked areas of SUN2-NBs, green marked Cajal bodies, and nucleolar regions encircled by the dotted white line. Bar $10 \mu \mathrm{m}$

NBs observed in interphase nuclei. The supporting evidence for such a possibility has come from co-localization assay using pulse 5-ethynyl-2'deoxyuridine (EdU) incorporation into DNA during the final stages of the $S$ phase (Fig. 7). Due to the highly polarized arrangement of onion cell nuclei, interphase chromatin reveals a clear-cut separation of centromeres and telomeres, which comprise latereplicating heterochromatic domains of the genome (Fussell 1975; Fujishige and Taniguchi 1998; Żabka et al. 2012). Both in the control (Fig. 7a-a $\mathrm{a}^{\prime \prime}$ ) and HU-pretreated RAM cells ( $48 \mathrm{~h}$ incubation; Fig. $7 \mathrm{~b}-\mathrm{b}^{\prime \prime}$ ), the occurrence of SUN2-NBs has been found confined exclusively to the EdU-labeled regions of pericentric chromatin, with no colocalization signals detected in the dispersed areas of telomeres, situated at the opposite side of the nucleus.

\section{SUN2-LPs localize also to preprophase band of microtubules}

Numerous enlarged cells appearing on the third day of DNA replication stress allowed for a more accurate 

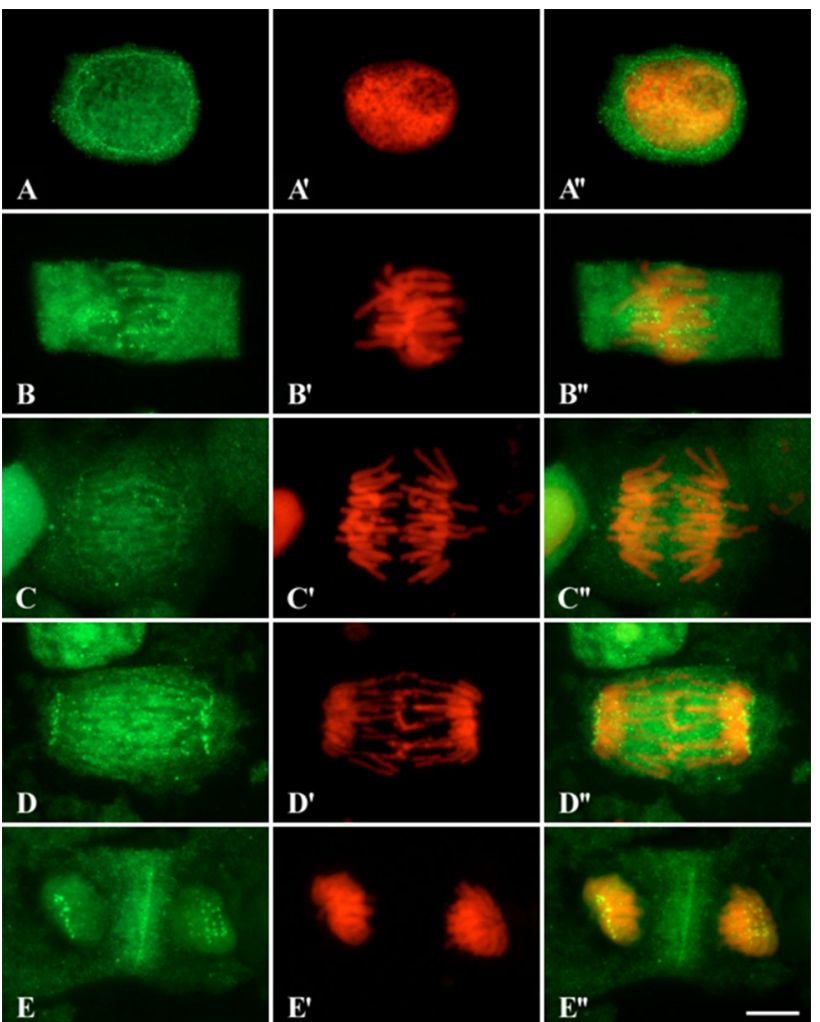

D
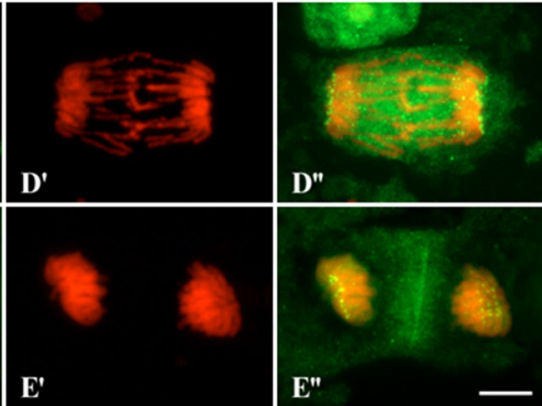

Fig. 6 Immunofluorescence of SUN2-LPs (Alexa Fluor ${ }^{\circledR} 488$, green) in mitotic root meristem cells of $A$. cepa after 48-h treatment with $0.75 \mathrm{mM}$ HU. a Prophase cell showing rim-like SUN2 immunofluorescence in nuclear envelope, $\mathbf{b}$ metaphase, $\mathbf{c}$ early anaphase, $\mathbf{d}$ late anaphase with chromosomes showing SUN2-LP localization at some centromeres, e telophase; note localization of SUN2-LPs at 16 centromeric regions and an intense labeling of phragmoplast and cell plate regions. $\mathbf{a}^{\prime}-\mathbf{e}^{\prime}, \mathbf{a}^{\prime \prime}-\mathbf{e}^{\prime \prime}$ Show the same cells $(\mathbf{a}-\mathbf{e})$ counterstained with PI (red) and shown merged, respectively. Bar $10 \mu \mathrm{m}$
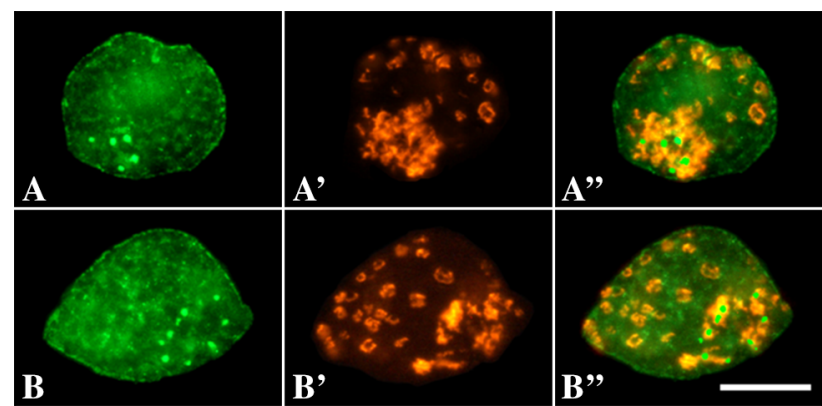

Fig. 7 Co-localization of SUN2-NBs (a, b; Alexa Fluor ${ }^{\circledR} 488$, green $)$ and EdU-labeled $\left(\mathbf{a}^{\prime}, \mathbf{b}^{\prime}\right.$; Alexa Fluor ${ }^{\circledR} 555$, orange $)$ areas of latereplicating heterochromatin during the final stages of $\mathrm{S}$ phase; a control, b cell nucleus from onion seedling pretreated for $48 \mathrm{~h}$ with $0.75 \mathrm{mM}$ HU. The same nuclei are shown merged $\left(\mathbf{a}^{\prime \prime}-\mathbf{b}^{\prime \prime}\right)$ with green marked areas corresponding to SUN2-NBs. Bar $10 \mu \mathrm{m}$

characterization of the axially elongated nuclei either predisposed to or having an advanced IM biphasic organization of chromatin. Despite rigorous screening of hundreds of biphasic G2/early prophase cells, none of them provided evidential support for a gradual or abrupt degradation of the NE membranes taking place in a more or less defined region somewhere in between the condensed (mitotic) and dispersed (interphase) parts of the nucleus. Consequently, the most prolonged period of HU treatment resulted in the formation of elongated mitotic cell nuclei only either with (Fig. 8a-a $\mathrm{a}^{\prime \prime}$ ) or without NE membranes stained with antiSUN2 antibodies (Fig. 8b-b ${ }^{\prime \prime}$ ). About $15 \%$ of all prophase cells revealed well preserved immunofluorescently labeled PPBs localized underneath the plasma membrane in the midplane of the nucleus (Fig. 8b, $\mathrm{b}^{\prime \prime}$ ). In most cases, SUN2-LP-rich ring-shaped PPB structures formed nuclear constrictions (evidenced in Fig. 8b), also discernible in largely elongated prophase cells after immunocytochemical staining of microtubules (Fig. 8c, d). The reminiscent effect of the tightening force exerted by PPB shrinkage in HU-treated cells became even more apparent at later stages of mitosis, as resolved by the bundles of compressed Feulgen-stained chromosomes shown in Fig. 8e and f.

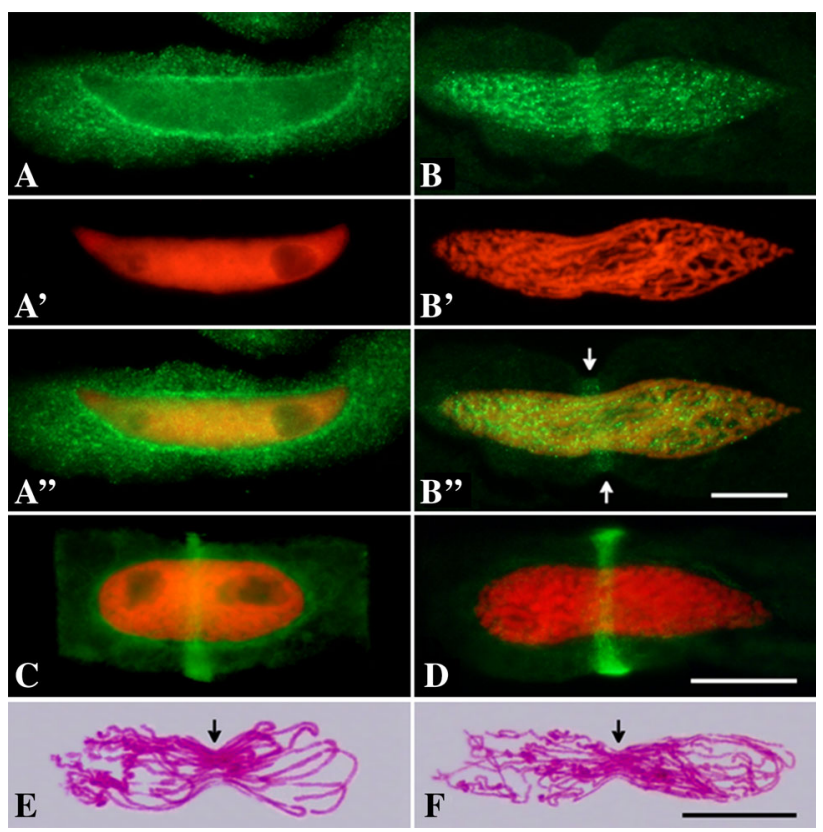

Fig. 8 Largely elongated root meristem cells of A. cepa after 3-day treatment with $0.75 \mathrm{mM}$ HU. a G2-phase cell showing immunolocalization of SUN2-LPs in the nuclear envelope, b M-phase cell displaying asynchronous chromatin condensation during transition from early-to-late prophase with a ring-like immunofluorescence of SUN2-LPs localized in the PPB region. $\mathbf{a}^{\prime}, \mathbf{b}^{\prime}$ The same cells (a, b) counterstained red with PI (red) and shown merged $\left(\mathbf{a}^{\prime \prime}, \mathbf{b}^{\prime \prime}\right)$. $\mathbf{b}^{\prime \prime}$ PPB region exerting some tightening force on the condensing chromosomes (arrows). c, $\mathbf{d}$ Immunofluorescence of $\beta$-tubulin (green) in prophase cells counterstained with PI $(r e d)$; c control, d HU treatment. Examples of Feulgen-stained chromosomes in late prophase cells from HU-treated onion seedlings (e, f); note some contractions induced by PPBs in the bunches of condensing chromosomes (arrows). Bars $10 \mu \mathrm{m}$ 


\section{Discussion}

Despite the unknown extent of sequence similarity between SUN2 proteins in evolutionarily distinct species, there seems to be an obvious structural and functional homology of these proteins manifested by their immunogenicity, common localization and interaction partners in plants and animals. Immunohistochemical and immunofluorescence labeling of the root apical meristems cells in Allium cepa indicates that most of the binding sites for the antibodies used in our experiments correspond well to the known localizations of SUN2 proteins, including nuclear membranes and two plant-specific regions, i.e. phragmoplast (composed of vesicles, microtubules and actin microfilaments) and the cell plate (Graumann and Evans 2011; Oda and Fukuda 2011). As evidenced previously (Żabka et al. 2012), alterations in the cell cycle progression in onion roots exposed to prolonged DNA replication stress are correlated with a considerable reprogramming of chromatin functions, enhanced production of $\mathrm{H}_{2} \mathrm{O}_{2}, \gamma$-phosphorylation of $\mathrm{H} 2 \mathrm{AX}$ histones and an abnormal pattern of DNA replication. Accordingly, an increased amount of SUN2-LPs in HU-treated onion seedlings may be reminiscent to the coordinated activation of metabolic pathways under replication stress conditions.

Substantial experimental support for the mediatory role of SUN-domain proteins in the DNA damage response functions has been recently obtained by Lei et al. (2012) in their studies on mouse embryonic fibroblasts (MEFs). As evidence of this, MEFs from Sun $1^{-/}$Sun $2^{-I}$ double knockouts revealed premature proliferation arrest in $\mathrm{S}$ phase of cell cycle, slightly increased incidence of apoptosis, excessive DNA damage, and decreased levels of perinuclear heterochromatin. Furthermore, in HU-treated Sun $1^{-/}$Sun2 ${ }^{-/-}$MEFs (in contrast to wild-type MEFs), no activation of ATM kinase and only a slight $\gamma$-phosphorylation of H2AX histones could be observed, suggesting prominent role of both SUN-domain proteins in the mechanism employed to maintain or to restore genetic stability (Lei et al. 2012). In view of that, an increased amount of SUN2-LPs observed in onion RAM cells exposed to prolonged HU treatment might also well be regarded as part of the nuclear mechanism specifically activated in response to DNA replication stress conditions. However, regardless of the proven effects of $\mathrm{HU}$ on replication forks and postreplication DNA repair capacities, low concentration of the drug applied in experiments on Allium cepa seedlings allows for continuous root growth, giving cells time to accumulate structural and regulatory proteins required for mitotic stimulation.

In addition to NE membranes, phragmoplast and cell plate, our immunofluorescence observations extend an array of subcellular compartments defined by anti-SUN2 antibodies. These include distinct areas of condensed chromosomes corresponding to their pericentric regions (observed in late anaphase and in telophase), the preprophase band (PPB) of microtubules, and perhaps the most amazing environment for proteins sharing SUN2-like epitopes, i.e. SUN2-containing nuclear bodies (SUN2NBs) polarly localized in interphase chromatin. Consistently with cytological and biochemical observations in animal cells, a large number of discrete nucleoplasmic compartments, jointly termed as nuclear bodies (NBs), are considered as "storage depots" for particular proteins released upon changing external factors, such as heat shock, heavy metals, viral infection, and DNA damage (Shaw and Brown 2004; Zimber et al. 2004; Dundr and Misteli 2010; Mao et al. 2011). This has prompted us to take a closer look at Cajal bodies as hypothetical structures involved in accumulation of SUN2-LPs. However, such a possibility has been ruled out by separate localization of epitopes recognized by antibodies specific for SUN2 and fibrillarin.

Instead, immunofluorescence survey throughout successive stages of the cell cycle strongly suggests a direct link between the anti-SUN2-labeled pericentric regions of anaphase and telophase chromosomes and the SUN2-NBs detected in interphase nuclei. At least two overlapping observations seem to provide arguments in favor of such a connection. The first refers to the uneven distribution of SUN2-NBs, reflecting a highly polarized arrangement of onion cell nuclei (Żabka et al. 2012). The second is based on the overlaid areas occupied by SUN2-NBs and latereplicating domains of EdU-labeled chromatin. Still another argument can be given in quantitative terms while considering a reduced number of SUN2-NBs distributed in interphase nuclei, as compared to the number of mitotic chromosomes labeled with anti-SUN2 antibodies. A probable cause of this difference relies in the centromere clustering, which seems to be one of the many instruments contributing to the higher-order organization of constitutive heterochromatin in different cell types of higher eukaryotes (Padeken and Heun 2013). Furthermore, such an assumption is particularly well designed to describe relatively frequent associations between centromeres and nucleoli (Padeken et al. 2013), and it seems consistent with a more general role suggested for the NE proteins in the maintenance of gene-poor, late-replicating domains of heterochromatin (Vanrobays et al. 2013; Tatout et al. 2014).

Until now, SUN2-centromere connections have been postulated to play a role in efficient coupling of heterochromatin DNA to the SUN-KASH complex in Schizosaccharomyces pombe, thus contributing as a 
reliable basis for the model of communication between cytoplasmic microtubules and chromatin (King et al. 2008). In A. cepa, apparent associations between SUN2LPs and pericentric regions of sister chromatids appear no sooner than after the kinetochores reach their most distant locations. It may thus be thought that the observed complexes represent the early centers designed to reconstitute $\mathrm{NE}$ membranes and/or to stabilize interactions between precursor vesicles of NE and chromatin. Such a viewpoint would be consistent with the observation that the NEmembrane components reside in close proximity to chromatin throughout division, and that the progression of $\mathrm{NE}$ initiates at the chromatin surface facing the spindle poles of the cell (Graumann and Evans 2011).

Another relationship that occurs between the preprophase band (PPB) and SUN2-LPs (formed exclusively after the prolonged treatment with $\mathrm{HU}$ ) adds a new problem that needs to be solved in the future. Despite the lack of evidential support for the SUN2-LP-PPB assemblages in other plant species, there is at least one molecular pathway by which a useful description of how this happens may be offered. Recently, AtSUN-AtWIP1 complex was recognized as an important mediator required for the NE localization of AtRanGAP1 and for preserving the elongated shape of plant cell nuclei (Zhou et al. 2012). Among many plant NE components, Ran, RanGAP, WIPs and WITs (WPP-interacting tail-anchored protein) have been found to localize to the cell plate. Furthermore and most importantly, Arabidopsis RanGAP1 was found to continuously concentrate at the PPB and the cortical division site during mitosis and cell division. Therefore, consistent with the cytokinesis defects, RNAi-induced depletion of RanGAP1 produced incomplete and irregularly positioned cell walls (Xu et al. 2008; Meier and Brkljacic 2009). It is reasonable to assume, than, that the structural basis of PPB, consisting of microtubules and vesicular elements (McMichael and Bednarek 2013), and its biochemical attributes (including RanGAP and other Ran-cycle proteins), can provide an integration platform for SUN2-LP and a clue to understand its new localization.

The obtained data appear to be insufficient to draw conclusions regarding functional relationships between an increased level of SUN2-LPs and a number of intracellular structures to which these proteins are preferentially localized both in normal onion RAM cells and after their prolonged treatment with HU. Clearly, however, most of these sites create temporary or permanent links with a variety of microtubular arrays involved in the stabilization of cell nuclei, in the mechanisms of chromosomal segregation, and in the determination of the axis and the symmetry of cell division. Consistently with such an assumption, an enhanced expression of flexible and extremely mobile SUN2 (or SUN2-LPs) under DNA replication stress conditions may appear advantageous to the cell by providing a broader range of regulatory possibilities.

Author contribution statement A.Ż. and J.M. equally participated in the conception and design of the study. A. $\dot{Z}$. contributed also to acquisition of the results and performed most of the analyses. K.W. contributed to the analysis of data and to the revision of the manuscript. J.T.P. and J.B. participated in immunofluorescence procedures. J.M. contributed to the English version of the text.

Acknowledgments This work was supported by a grant (N N303 503038) from National Science Centre (Poland).

\section{Compliance with ethical standards}

Conflict of interest The authors declare that they have no conflict of interest.

Open Access This article is distributed under the terms of the Creative Commons Attribution 4.0 International License (http://crea tivecommons.org/licenses/by/4.0/), which permits unrestricted use, distribution, and reproduction in any medium, provided you give appropriate credit to the original author(s) and the source, provide a link to the Creative Commons license, and indicate if changes were made.

\section{References}

Amin MA, Matsunaga S, Ma N, Takata H, Yokoyama M, Uchiyama S, Fukus K (2007) Fibrillarin, a nucleolar protein, is required for normal nuclear morphology and cellular growth in HeLa cells. Biochem Biophys Res Commun 360:320-326

Bensimon A, Aebersold R, Shiloh Y (2011) Beyond ATM: the protein kinase landscape of the DNA damage response. FEBS Lett 585:1625-1639

Dundr M, Misteli T (2010) Biogenesis of nuclear bodies. Cold Spring Harb Perspect Biol 2:a000711

Evans DE, Shvedunova M, Graumann K (2011) The nuclear envelope in the plant cell cycle: structure, function and regulation. Ann Bot 107:1111-1118

Fujishige I, Taniguchi K (1998) Sequence of DNA replication in Allium fistulosum chromosomes during S-phase. Chromosome Res 6:611-619

Fussell CP (1975) The position of interphase chromosomes and late replicating DNA in centromere and telomere regions of Allium cepa L. Chromosoma 50:201-210

Gall JG (2000) Cajal bodies: the first 100 years. Annu Rev Cell Dev Biol 16:273-300

Graumann K, Evans DE (2010) Plant SUN domain proteins. Components of putative plant LINC complexes? Plant Signal Behav 5:154-156

Graumann K, Evans DE (2011) Nuclear envelope dynamics during plant cell division suggest common mechanisms between kingdoms. Biochem J 435:661-667

Graumann K, Runions J, Evans DE (2010) Characterization of SUNdomain proteins at the higher plant nuclear envelope. Plant $\mathbf{J}$ 61:134-144

Hodzic DM, Yeater DB, Bengtsson L, Otto H, Stahl PD (2004) Sun2 is a novel mammalian inner nuclear membrane protein. $\mathrm{J}$ Biol Chem 279:25805-25812 
King MC, Drivas TG, Blobel G (2008) A network of nuclear envelope membrane proteins linking centromeres to microtubules. Cell $134: 427-438$

Lei K, Zhu X, Xu R, Xu T, Zhuang Y, Han M (2012) Inner nuclear envelope proteins SUN1 and SUN2 play a prominent role in the DNA damage response. Curr Biol 22:1609-1615

Liu S, Opiyo SO, Manthey K, Glanzer JG, Ashley AK, Amerin C, Troksa K, Shrivastav M, Nickoloff JA, Oakley GG (2012) Distinct roles for DNA-PK, ATM and ATR in RPA phosphorylation and checkpoint activation in response to replication stress. Nucleic Acids Res 40:10780-10794

Mao YS, Zhang B, David L, Spector DL (2011) Biogenesis and function of nuclear bodies. Trends Genet 27:295-306

McMichael CM, Bednarek SY (2013) Cytoskeletal and membrane dynamics during higher plant cytokinesis. New Phytol 197:1039-1057

Meier I, Brkljacic J (2009) The nuclear pore and plant development. Curr Opin Plant Biol 12:87-95

Moriguchi K, Suzuki T, Ito Y, Yamazaki Y, Niwa Y, Kurata N (2005) Functional isolation of novel nuclear proteins showing a variety of subnuclear localizations. Plant Cell 17:389-403

Murphy SP, Bass HW (2012) The maize (Zea mays) desynaptic (dy) mutation defines a pathway for meiotic chromosome segregation, linking nuclear morphology, telomere distribution and synapsis. J Cell Sci 125:3681-3690

Murphy SP, Simmons CR, Bass HW (2010) Structure and expression of the maize (Zea mays L.) SUN-domain protein gene family: evidence for the existence of two divergent classes of SUN proteins in plants. BMC Plant Biol 10:269

Oda Y, Fukuda H (2011) Dynamics of Arabidopsis SUN proteins during mitosis and their involvement in nuclear shaping. Plant $\mathbf{J}$ 66:629-641

Padeken J, Heun P (2013) Centromeres in nuclear architecture. Cell Cycle 12:3455-3456

Padeken J, Mendiburo MJ, Chlamydas S, Schwarz HJ, Kremmer E, Heun P (2013) The nucleoplasmin homolog NLP mediates centromere clustering and anchoring to the nucleolus. Mol Cell 50:236-249

Paull TT, Rogakou EP, Yamazaki V, Kirchgessner CU, Gellert M, Bonner WM (2000) A critical role for histone H2AX in recruitment of repair factors to nuclear foci after DNA damage. Curr Biol 10:886-895

Rybaczek D, Maszewski J (2007) Phosphorylation of H2AX histones in response to double-strand breaks and induction of premature chromatin condensation in hydroxyurea-treated root meristem cells of Raphanus sativus, Vicia faba, and Allium porrum. Protoplasma 230:31-39

Schmitt J, Benavente R, Hodzic D, Höög C, Stewart CL, Alsheimer M (2007) Transmembrane protein Sun2 is involved in tethering mammalian meiotic telomeres to the nuclear envelope. Proc Nat Acad Sci USA 104:7426-7431

Shaw PJ, Brown JW (2004) Plant nuclear bodies. Curr Opin Plant Biol 7:614-620

Stiff T, O'Driscoll M, Rief N, Iwabuchi K, Löbrich M, Jeggo PA (2004) ATM and DNA-PK function redundantly to phosphorylate $\mathrm{H} 2 \mathrm{AX}$ after exposure to ionizing radiation. Cancer Res 64:2390-2396

Tatout C, Evans DE, Vanrobays E, Probst AV, Graumann K (2014) The plant LINC complex at the nuclear envelope. Chromosome Res 22:241-252

Vanrobays E, Thomas M, Tatout C (2013) Heterochromatin positioning and nuclear architecture. Plant Nucl Struct Genome Archit Gene Regul. Wiley-Blackwell, 157-190

Wang Q, Du X, Cai Z, Greene MI (2006) Characterization of the structures involved in localization of the SUN proteins to the nuclear envelope and the centrosome. DNA Cell Biol 10:554-562

Xu XM, Zhao Q, Rodrigo-Peiris T, Brkljacic J, He CS, Müller S, Meier I (2008) RanGAP1 is a continuous marker of the Arabidopsis cell division plane. Proc Nat Acad Sci USA 105:18637-18642

Żabka A, Polit JT, Maszewski J (2010) Inter- and intrachromosomal asynchrony of cell division cycle events in root meristem cells of Allium cepa: possible connection with gradient of cyclin B-like proteins. Plant Cell Rep 29:845-856

Żabka A, Polit JT, Maszewski J (2012) DNA replication stress induces deregulation of the cell cycle events in root meristems of Allium cepa. Ann Bot 110:1581-1591

Żabka A, Trzaskoma P, Maszewski J (2013) Dissimilar effects of $\beta$ lapachone- and hydroxyurea-induced DNA replication stress in root meristem cells of Allium cepa. Plant Physiol Biochem 73:282-293

Zhou X, Graumann K, Evans DE, Meier I (2012) Novel plant SUNKASH bridges are involved in RanGAP anchoring and nuclear shape determination. J Cell Biol 196:203-211

Zimber A, Nguyen QD, Gespach C (2004) Nuclear bodies and compartments: functional roles and cellular signalling in health and disease. Cell Signal 16:1085-2104 